$$
\text { Pontifícia } U_{\text {niversidade }} \text { Católica }_{\text {Do Rio de Janeiro }}
$$

Rosania de Almeida de Lima

\title{
TRABALHO, FAMÍLIA, AMIGOS: Construções de Identidade de um Migrante Nordestino no Rio de Janeiro em Entrevista de Pesquisa
}

Dissertação de Mestrado

Dissertação de Mestrado apresentada como requisito parcial para obtenção do grau de Mestre em Letras do Departamento de Letras da PUC-Rio como parte dos requisitos parciais para obtenção do título de Mestre em Letras.

Orientadora: Profa. Dra. Maria das Graças Dias Pereira Co-orientadora: Profa. Dra. Clarissa Rollin Pinheiro Bastos

Rio de Janeiro

Dezembro de 2008 


$$
\text { Pontifícia } U_{\text {niversidade }} \text { Católica }_{\text {Do Rio de Janeiro }}
$$

Rosania de Almeida de Lima

\title{
TRABALHO, FAMÍLIA, AMIGOS: Construções de Identidade de um Migrante Nordestino no Rio de Janeiro em Entrevista de Pesquisa
}

\begin{abstract}
Dissertação apresentada como requisito parcial para obtenção do grau de Mestre pelo programa de PósGraduação em Letras do Departamento de Letras do Centro de Teologia e Ciências Humanas da PUC-Rio. Aprovada pela Comissão Examinadora abaixo assinada.
\end{abstract}

Profa. Dra. Clarissa Rollin Pinheiro Bastos

Co-orientadora

Departamento de Letras - PUC-Rio

Profa. Dra. Liliana Cabral Bastos

Departamento de Letras - PUC-Rio

Profa. Dra. Sonia Bittencourt Silveira

Universidade Fderal de Juiz de Fora - UFJF

Prof. Dr. Paulo Fernando Carneiro de Andrade Coordenador Setorial do Centro de Teologia e Ciências Humanas - PUC-Rio

Rio de Janeiro, de de 
Todos os direitos reservados. É proibida a reprodução total ou parcial do trabalho sem autorização da universidade, da autora e da orientadora.

\section{Rosania de Almeida de Lima}

Graduou-se como Bacharel em Letras, com licenciatura plena em Português-Inglês pela UFRJ (Universidade Federal do Rio de Janeiro) em 1983. É professora de Inglês-Português, tendo atuado nos últimos anos nas áreas de Língua Portuguesa e Inglesa. Participou de Congresso na área de Sociolingüística, debates na área de Análise do Discurso, de curso na área de Antropologia, e apresentou comunicação na área de Letras. Faz parte do Grupo de Pesquisa: Linguagem, cultura e trabalho, na PUC-Rio.

Ficha Catalográfica

Lima, Rosania de Almeida de

Trabalho, família, amigos : construções de identidade de um migrante nordestino no Rio de Janeiro em entrevista de pesquisa / Rosania de Almeida de Lima ; orientadora: Maria das Graças Dias Pereira ; co-orientadora: Clarissa Rollin Pinheiro Bastos. - 2008.

132 f. ; $30 \mathrm{~cm}$

Dissertação (Mestrado em Letras) - Pontifícia Universidade Católica do Rio de Janeiro, Rio de Janeiro, 2008.

Inclui bibliografia

1. Letras - Teses. 2. Migrante nordestino. 3. Identidade. 4. Cultura. 5. História de vida. 6. Trabalho. 7. Família. 8. Amigos. 9. Entrevista. 10. Interação. I. Pereira, Maria das Graças Dias. II. Bastos, Clarissa Rollin Pinheiro. III. Pontifícia Universidade Católica do Rio de Janeiro. Departamento de Letras. IV. Título. 


\section{Agradecimentos}

A Jesus por me mostrar que o sol nasce todos os dias.

À minha orientadora Maria das Graças Dias Pereira e co-orientadora Clarissa Rollin Pinheiro Bastos, por todo conhecimento compartilhado e pela paciência e carinho, sem os quais este trabalho não poderia ter sido realizado.

À CAPES e CNPq pela bolsa concedida em incentivo à pesquisa, essencial para o desenvolvimento sociocultural do país.

À PUC-Rio pela bolsa de isenção concedida, que me proporcionou a oportunidade de aprimorar meus conhecimentos para a realização dessa pesquisa.

Ao meu filho Rodrigo, pelo apoio e palavras de incentivo, por enxugar minhas lágrimas, por não me deixar desanimar, por me fazer sentir sempre jovem, por segurar minhas mãos, por acreditar em mim e por fazer parte da minha maior torcida.

À minha filha Lara, por estar ao meu lado em todos os momentos, por tantas vezes me aconchegar em seu colo e disfarçar que não estava chorando comigo, por me fazer rir com ela, por acreditar em mim, pelo carinho, paciência, incentivo e por também fazer parte da minha maior torcida.

Ao Seu Francisco que tão gentilmente me cedeu o precioso tempo de sua vida para a realização das entrevistas que enriqueceram essa pesquisa.

Ao professor William Soares dos Santos que gentilmente contribuiu com sugestões importantes para a realização deste trabalho.

À professora Liliana Cabral Bastos pelo conhecimento compartilhado durante suas aulas.

À minha amiga Rosa que possibilitou o meu encontro com Seu Francisco para a realização das entrevistas.

Às minhas amigas de luta, Regysane, Sandra e Jaqueline, pelas palavras de segurança, apoio técnico e por me dar as mãos em vários momentos.

À minha amiga Marta, que esteve comigo desde o início.

Ao Grupo de Pesquisa: Linguagem, cultura e trabalho que colaborou com importantes sugestões.

À Chiquinha e todos da Secretaria de Pós-Graduação, que sempre estiveram e estão prontos para ouvir e ajudar. 


\section{Resumo}

Lima, Rosania de Almeida de; Pereira, Maria das Graças Dias (Orientadora); Bastos, Clarissa Rollin Pinheiro (Co-orientadora). TRABALHO, FAMÍlIA, AMIGOS: Construções de Identidade de um Migrante Nordestino no Rio de Janeiro em Entrevista de Pesquisa. Rio de Janeiro, 2008. 132p. Dissertação de Mestrado - Departamento de Letras. Pontifícia Universidade Católica do Rio de Janeiro.

Os objetivos desta dissertação são analisar as (re)construções identitárias sócio-culturais de um migrante nordestino no Rio de Janeiro que emergem em sua história de vida e refletir sobre o processo sócio-histórico-cultural da migração no Brasil, particularmente a partir de 1930, e suas relações com as situações vivenciadas por esse migrante em Lagoa da Roça, Paraíba, e no Rio de Janeiro, cidade para a qual migra. Este estudo desenvolve-se em uma perspectiva sociointeracional para a análise do discurso junto a concepções de identidade(s) de ordem sócio-cultural e interacional, informadas pela ordem micro e macro do discurso. Os dados de análise consistem de duas gravações em áudio, obtidas através de entrevistas de pesquisa. Insere-se, assim, na tradição de pesquisa qualitativa e interpretativa. Seu Francisco, o entrevistado, tem 50 anos de idade e é porteiro há vinte e oito anos no prédio onde foram realizadas as entrevistas. Ele migra para o Rio de Janeiro em busca de melhores oportunidades de trabalho. $\mathrm{Na}$ análise, focalizam-se os posicionamentos do entrevistado tendo em vista as narrativas, explicações e crônicas construídas na interação com o entrevistador em torno do processo de migração, da família, do trabalho e dos amigos configurados em sua história. Os resultados deste estudo mostram o quanto conflituoso foi o processo de mudança sócio-cultural desse nordestino, que se constrói como um homem agentivo, cujas ações orientam-se para a autonomia, na roça, enquanto, no Rio de Janeiro, Seu Francisco mostra-se mais passivo, com menos iniciativa e sem expectativas definidas.

\section{Palavras-chave}

Migrante nordestino, identidade, cultura, história de vida, trabalho, família, amigos, entrevista, interação. 


\section{Abstract}

Lima, Rosania de Almeida de; Pereira, Maria das Graças Dias (Supervisor); Bastos, Clarissa Rollin Pinheiro (Co-Supervisor). WORK, FAMILY, FRIENDS: Identities Construction of a northeastern migrant in Rio de Janeiro through Research Interview. Rio de Janeiro, 2008. 132p. MSc Dissertation - Departamento de Letras, Pontifícia Universidade Católica do Rio de Janeiro.

The objectives of this study are to analyze the (re) construction of the socio-cultural identities of a northeastern migrant in Rio de Janeiro that emerge in his life story and reflect on the socio-historical-cultural migration process in Brazil, particularly from 1930, and its relations with the situations experienced by the migrant in Lagoa da Roça, Paraíba, and Rio de Janeiro, city to where he migrates. This study is developed in a sociointeractional perspective, analyzing the speech from the socio-cultural and interactional concepts of identity, informed by the micro and macro speech. The data for analysis consist of two recordings on audio, obtained through interview research, following the tradition of qualitative and interpretative research. S. Francisco, the interviewee, is 50 years old and has been a doorman for twenty-eight years in the building where the interviews were conducted. He migrates to Rio de Janeiro seeking better job opportunities. In the analysis, the interviewee's positions are focused in view of the narratives, explanations and chronics about the process of migration, family, work and friends set in his story, which are constructed in interaction with the interviewer. The results of this study show how conflictuous has been the process of the sociocultural change in that northeastern migrant life, who constructs the identity of an agentive man, whose actions are moving towards his autonomy in the countryside, while in Rio de Janeiro, S. Francisco shows to be more passive, with less initiative and without defined expectations.

\section{Keywords}

Northeastern migrant, identity, culture, life story, work, family, friends, interview, interaction. 


\section{Sumário}

1. Introdução 9

2. Contextualização sócio-histórica: Estudo sobre as migrações nordestinas no Brasil

2.1. Migrantes nordestinos no mercado de trabalho no Rio de Janeiro: porteiros (empregados) de edifício

3. Fundamentação teórica

3.1. Construção de identidade sócio-cultural e interacional 23

3.2. História de vida

3.3. Sociolingüística interacional

4. Metodologia e dados de pesquisa 36

4.1. Entrevista de pesquisa qualitativa 38

4.2. Contextualização dos dados $\quad 41$

5. Análise dos dados $\quad 44$

5.1. A motivação do processo de migração 44

5.2. Trabalho 54

5.2.1. Trabalho na roça $\quad 54$

5.2.2. Trabalho com o pai $\quad 60$

5.2.3. Trabalho no Rio de Janeiro 63

5.3. Família e amigos $\quad 75$

$\begin{array}{ll}\text { 5.3.1. Na terra de origem } & 75\end{array}$

$\begin{array}{ll}\text { 5.3.2. No Rio de Janeiro } & 81\end{array}$

5.4. As tentativas de retorno e as razões de permanência 92

5.5. Sonhos realizados 98

6. Considerações finais 101

Referências bibliográficas $\quad 109$

$\begin{array}{ll}\text { Anexos } & 113\end{array}$ 
Águas profundas são as palavras da boca do homem, e ribeiro transbordante é a fonte da sabedoria

Provérbios 18:4

"lembrar não é reviver, mas refazer, reconstruir, repensar, com imagens e idéias de hoje, as experiências do passado"

Bosi

"Ninguém se banha duas vezes no mesmo rio"

Heráclito

“na segunda vez, já não é a mesma pessoa, já não é o mesmo rio”

Bagno

Mas os que esperam no Senhor renovam as suas forças, sobem com asas como águias; correm e não se cansam; caminham e não se fatigam.

Isaías 40:31 